\title{
A deficiência mental na CONCEPÇÃo da liga brasileira de higIENe MENTAL
}

M ENTAL DISABILITY IN THE CONCEPTION OF BRAZILIAN LEAGUE OF MENTAL HYGIENE

Milena Luckesi de SOUZA ${ }^{1}$

Maria Lucia BOARINI²

\begin{abstract}
RESU M O: o objetivo deste texto é investigar a concepção e as propostas de atendimento escolar destinado aos deficientes mentais segundo o ideário higienista e eugenista difundido pela Liga Brasileira de $\mathrm{H}$ igiene $\mathrm{M}$ ental (LBHM). Para tanto, utilizamos como fonte primária de estudo os A rquivos Brasileiros de H igiene M ental (ABHM), periódico publicado entre 1925 e 1947. Verificamos quea LBHM expressa diferentes opiniões quanto à concepção e às medidas de intervenção propostas para os deficientes mentais. De um lado, propõe a higienização da população, a ser al cançada com a formação de hábitos sadios através da educação escolar e especificamente da educação higiênica, com a possível adaptação do deficiente ao meio social. De outro, defende uma posição eugênica radical, que apregoa a purificação da raça, a esterilização e exclusão dos ditos degenerados (leprosos, loucos, idiotas, epilépticos, cancerosos, nefrolíticos, tuberculosos, prostitutas, vagabundos edeficientes mentais).
\end{abstract}

PALA V RA S-CHA VE: deficiência mental; educação escolar; Arquivos Brasileiros de Higiene Mental, higiene mental e eugenia, educação especial.

A BSTRACT: the aim of this study is to investigate the conception and proposals of schooling for individuals with mental disability according to the hygienic and eugenic ideology divulged by the Brazilian League for Mental Hygiene (Liga Brasileira de H igiene M ental, LBHM). To this end, we used as a primary source the Brazilian A rchives of $M$ ental $\mathrm{H}$ ygiene (A rquivos Brasileiros de $\mathrm{H}$ igiene $\mathrm{M}$ ental, $\mathrm{ABHM}$ ), a newspaper published from 1925 to 1947. We concluded that there were various opinions in the LBHM about the conception and proposed intervention methods for individuals with mental disability. On one side, there were proposals of population cleansing to be achieved through healthy habits taught in schools, mainly hygienic education, with possible adaptation of the disabled individual to society. On the other hand, there was an extreme eugenic proposal that emphasized race purification, sterilization and exclusion of so-called degenerate individuals (lepers, lunatics, idiots, epileptics, cancer patients, nephrolytics, tuberculosis patients, prostitutes, vagrants and individuals with mental retardation).

KEYWOR D S: mental disability, schooling, Brazilian Archives of Mental Hygiene, mental hygieneand eugenics; special education.

\section{INTRODUÇÃo}

Este estudo tem como inspiração alguns questionamentos a respeito dos inúmeros movimentos sociais, discursos el egislações da atualidade, orientados para aintegração/ inclusão do indivíduo com deficiência (mental, física ou sensorial) em diversos setores da vida social, que no âmbito escolar visa à gradativa

\footnotetext{
${ }_{1}^{1}$ Psicóloga e M estre em Educação pela Universiadde Estadual de Maringá - milenaluckesi @hotmail.com

2 Doutora, Mestre e graduada em Psicologia. Professora Associada do Departamento de Psicologia e dos Programas de Pós-Graduação em Historia da Educação e de Psicologia da Universidade Estadual de Maringá - mlboarini@uol.com.br
} 
desativação de um sistema especial e paralelo de ensino para os indivíduos considerados deficientes.

Todavia, nossa proximidade com os fatos históricos dificulta a explicação da deficiência mental edeseus desdobramentos no campo da Educação Especial na atualidade. Esta dificuldade nos instiga a olhar para o passado na tentativa de compreender a construção histórica dos conceitos, dos discursos edas práticas vivenciadas no âmbito do atendimento escolar oferecido ao deficiente mental. Desta forma, retornamos as primeiras décadas do século XX eneste período delimitamos nosso estudo a compreensão da concepção e do atendimento escolar destinado ao deficientemental segundo o ideário higienista eeugenista difundido pela LBHM , que se propôs regularizar efortalecer as funções afetivas, intel ectuais e morais do indivíduo, bem como combater as causas determinantes das perturbações psíquicas. Para tanto, a educação seria o caminho mais curto.

A educação era vista por determinados segmentos da sociedade como uma condição essencial para o Brasil al cançar o progresso social e econômico. A escola, por sua vez, era considerada espaço estratégico para a divulgação e a prática da higiene mental e deveria estar orientada para defender a sociedade das patologias, da pobreza e do vício que se alastravam pelo país. Tendo em vista a ênfase dada à educação enquanto possibilidade de superação do atraso nacional, destacamos os encaminhamentos oferecidos pela LBHM no que tange a educação do deficiente mental.

Nosso estudo tem caráter temático, histórico e bibliográfico e se respaldou principalmente na leitura e análise dos ABHM (1925-1947), importante órgão de divulgação dos ideais higienistas e eugenistas.

Os ABHM tinham por objetivo fomentar o intercâmbio intelectual entre os neuropsiquiatras brasileiros eestrangeiros, estabel ecendo trocas eintensificando relações com as princi pais bibliotecas e sociedades científicas do mundo (CALDAS, 1929, p. 2). Mas, os "ensinamentos úteis e práticos", contidos nos ABHM, não se destinavam apenas aos círculos científicos ou aos setores especializados da psiquiatria, visavam também à massa popular, a qual procuravam orientar no sentido da conservação da saúde do espírito (NOTA ..., 1947, p.3).

Percorremos o interior dos ABHM através de uma leitura de reconhecimento e nos deparamos com uma diversidade de temas rel acionados ao al cool ismo, à educação, à infância, aos testes psicológicos, à imigração, à eugenia, à delinqüência, dentre outros, que ocupavam as discussões dos higienistas em congressos, aulas, palestras radi ofônicas, campanhas, publicações, erequisitavam explicações e encaminhamentos.

Selecionamos, para nossa análise, textos que nos auxiliassem a compreender o desenvolvimento da higiene mental no Brasil e sua interlocução com os princípios da eugenia, bem como a concepção de deficiência mental e as respectivas propostas de atendimento escolar oferecido aos deficientes. 


\section{A Liga Brasileira de Higiene Mental e seu enfoque preventivo}

De início a higiene mental apresentou-se como um movimento que contestava o tratamento dispensado aos doentes mentais. O atendimento asilar estava sendo questionado na Europa e nos Estados Unidos. Combatiam-se os hospícios superlotados, as internações prolongadas eos tratamentos sem resultados. Buscavam-se alternativas para a medicina mental, pois o cotidiano mostrava quea sociedade progredia rapidamente trazendo consi go a loucura e a degeneração.

O movimento de higiene mental, com essa denominação, organizousea partir do início do século XX nos Estados Unidos. A publicação da autobiografia de Clifford Beers (1876-1943), A M ind that Found Itself, em 1908, relatando sua experiência de internação em vários hospitais e casas de saúde por um período de três anos, despertou a atenção dos neuropsiquiatras daquele país. Em maio de 1908, foi fundada a Sociedade de Higiene Mental de Connecticut e, em 1909, o Comitê Nacional de Higiene Mental em Nova Iorque, por meio do qual foram criados os chamados serviços abertos, os ambulatórios psiquiátricos e os serviços sociais. A partir das experiências dos Estados Unidos, o movimento difundiu-se para outros países.

Em 1923, o movimento de higiene mental é consolidado no Brasil através da criação da LBHM. Fundada no Rio de Janeiro, tendo à frente o médico Gustavo Riedel, dirigida por psiquiatras e composta demembros da el ite da classe médica brasileira e de juristas, educadores, jornalistas etc., a LBMH tornou-se o grande centro de propaganda em favor da higidez mental.

A LBHM era uma entidade civil mantida através de contribuições de filantropos e com uma subvenção federal, sendo a primeira A ssociação deM edicina Social da A mérica do Sul. A pós 1925, passou a ser mantida principalmente com a renda proveniente deanúncios contidos nos $A B H M$, quesegundo Fontenelle(1925) foram constituídos com a finalidade de divulgar as ações da Liga e "sobretudo a orientar os que desejem (desejassem) colaborar na campanha pela higienemental". Nesse sentido, pretendia-se que eles fossem "não só um repositório do que se publique sobre o assunto em nosso meio, ou al hures, mas também, se possível, um núcleo e atração de prosélitos, no amplo domínio dessa Higiene Mental, que com justo direito aspira tornar-se a 'moral universal de amanhã'” (p. 5).

Os objetivos da LBHM, deacordo com os seus estatutos, sedel inearam no sentido de alcançar:

[...] a) prevenção das doenças nervosas e mentais pela observância dos princípios da higiene geral eespecial do sistema nervoso; b) proteção eamparo no meio social aos egressos dos mani cômios eaos deficientes mentais passíveis de internação; c) mel horia progressiva nos mei os de assistir etratar os doentes nervosos e mentais em asil los públicos, particulares ou fora deles; d) realização deum programa deH igieneM ental edeEugenética no domínio das atividades individual, escolar, profissional e social (BRASIL, 1925, p. 223). 
A higienemental dividia-sebasicamenteem duas modalidades deação, positivas e negativas: "Dentro das primeiras incluem-setodas as sugestões que se destinem a promover a perfeita higidez mental dos indivíduos normais, cabendo as segundas - medidas de ordem propriamente profilática - o combate direto às causas de desarranjo mental" (LOPES, 1930c, p. 64).

Segundo Cal das (1932a), cabe à higiene mental manter o ajustamento das funções psíquicas individuais ao meio social ecósmico, ou vice-versa, evitando, deste modo, os desequilíbrios e desajustamentos que constituem as doenças mentais.

Olinto (1941) compartilhava da mesma opinião, enfatizando que os problemas da higiene mental são resultantes de questões de adaptação, de aprendizagem e deajustamento social. Para ele, os serviços dehigienemental que se restringiam aos estabelecimentos de assistência a psicopatas ou se limitavam a tratamento deanormais, controlados exclusivamente pelas organizações de saúde pública, nunca produziriam seus efeitos.

No parecer de Lopes (1944), a higiene mental constitui um dos mais importantes setores da medicina preventiva, visto que promove condições favoráveis e propícias para a conservação da saúde do espírito. Ninguém pode dispensar seus valiosos serviços e não existe campo de atividade humana em que ela não possa penetrar. A sua esfera de ação al cança todos os lugares em que o homem se encontra.

A higienemental propunha medidas decontrolesocial queabrangiam intervenções em diversas áreas esegmentos sociais: no lar, na escola, na organização do trabal ho, na vida militar, no ambiente colonial, no domínio criminológico, na produção literária e artística.

O programa higiênico abarcava variados aspectos da vida privada estendendo-se aos círculos da vida pública dos indivíduos e visava, sobretudo, prevenir o aparecimento de qualquer distúrbio físico, psíquico ou mental considerado inferiorizadores do povo de uma nação que al mejava estar entre as grandes do mundo recentemente gl obalizado. "O progresso e a grandeza de uma nação não depende somente da cultura do seu povo, senão também do equilíbrio, da justeza, da higidez, em suma, da sua mentalidade"' (CALDAS, 1930, p.35).

Deste modo, a higiene mental procurava promover condições especiais à conservação da saúde do espírito, da al egria de viver, velando pelo equilíbrio das funções psíquicas. "A medicina do futuro, não existea menor dúvida, seráa medicina preventiva, eà Higiene Mental cabe relevante papel” (LOPES, 1944, p. 69).

\section{A eUgenia: um "Novo" discurso Se aCresce ao ideÁrio higienista}

O termo eugenia (do grego eugenes = bem nascido) foi proposto em 1885, por Francis Galton (1822-1911), para designar o ramo da ciência biológica 
que se relaciona à melhoria genética da humanidade. Galton definiu a eugenia como o estudo dos fatores, sob control esocial, que podem mel horar ou aperfeiçoar as qualidades raciais de futuras gerações, fisicamente e mentalmente. Portanto, segundo Galton, eugenia é a ciência que se baseia nos princípios genéticos e no conhecimento das ciências sociais.

Conjugando um programa de higiene mental baseado na noção de prevenção eugênica, alguns higienistas, integrantes da $\mathrm{LBHM}^{3}$, apoiados nos inovadores conhecimentos científicos da psicometria eda genética, pilares da eugenia, entendiam que fatores intrínsecos aos indivíduos, tais como as características constitucionais de ordem física e psíquica determinadas pela herança genética, estariam contribuindo na formação de uma sociedade não tão desenvolvida como se esperava para o país. Neste sentido, a higiene mental toma para si a responsabilidade de interferir nessas condições para que os brasileiros fossem moldados segundo as necessidades do processo de desenvolvimento em ação.

Devido às possibilidades que eugenia oferecia como um instrumento para regenerar a saúde física, mental e moral da população, muitos higienistas assumiram o ideário científico da eugenia como discurso fundamental de seus projetos. Em grande medida isso ocorreu porque os problemas sociais como a criminalidade, delinqüência, prostituição, doenças mentais, vícios e pobreza eram cada vez mais associados ao patrimônio hereditário, o que fazia com que os intelectuais e boa parte da elite local acreditassem no importante papel que a eugenia poderia desempenhar para regenerar a raça nacional.

Reis (2003) considera queal guns acontecimentos podem ser apontados como tendo influência para a incorporação de medidas eugênicas mais radicais (esterilização compul sória ecasamentos controlados) no interior da LBHM a partir da virada do anos 30: a realização do Congresso Brasileiro de Eugenia, ocorrido em 1929; a conjutura política que começa a se insinuar mais intervencionista e antiliberal, mais propensa a ações ordenadoras e racionalizadoras da sociedade e a presença crescente do modelo eugênico alemão no Brasil.

No contexto brasileiro, a articulação entrehigienismo eeugenismo toma tamanha proporção que, em determi nado momento, a eugenia passa a ser entendida como parte do higienismo, como podeser constatado no discurso de Lopes (1930d), durante o II Congresso Brasileiro deHigiene, ocorrido em 1924, no qual afirma ser a eugenia um capítulo da higiene.

Embora alicerçados em circunstâncias históricas eproposições teóricas, decerta forma diferentes, o movimento eugenista e higienista aproximam-seatravés de suas preocupações e determinação de tornar o Brasil uma grande nação. Recorrendo às noções de higiene psíquica e racial, apoiando-se em conceitos das

\footnotetext{
${ }^{3}$ Cabe destacar, conforme Reis (2003), que, embora tivessem como eixo unificador de suas propostas a questão da prevenção eugênica, os psiquiatras no interior da LBHM apresentavam divergências quanto aos modos e limites de intervenção; diferenças de ordem religiosa, moral, política e até mesmo teórica.
} 
ciências naturais e utilizando-se dos métodos das ciências exatas, os higienistas identificados com os ideais eugênicos propunham-se a explicar e prevenir a incidência das doenças mentais e tantos outros problemas. Para estes, interessava a possibilidade apontada pelo eugenismo de utilização de todos os conhecimentos, no sentido demel horar física, mental eracialmente as futuras gerações brasileiras.

O ideal eugênico preconizava a formação de um novo homem moral, psíquica ebiologicamenteaperfeiçoado, diretamente oposto ao homem degenerado, combatido pelos intelectuais e médicos da época. A LBHM, identificada com este ideal, iria então buscar espaços vários em que pudesse intervir e colaborar para o aperfeiçoamento moral do cidadão e o melhoramento do nível da saúde mental.

Kehl (1935), um dos maiores propagandistas da eugenia no Brasil, integrante da LBHM, titular da seção de estudos sobre medicina geral e especializada em suas relações com o sistema nervoso, autor de vários artigos nos $\mathrm{ABHM}$, discriminava as ações do higienismo e da eugenia com as seguintes palavras:

[...] a higiene, por exemplo, procura melhorar as condições do meio e as individuais, para tornar os homens em melhor estado físico, a eugenia, intermediária entrea higiene social ea medicina prática, favorecendo os fatores sociais de tendência seletiva, se esforça pel o constantee progressivo multiplicar de indivíduos "bem dotados" ou eugenizados (p.46).

A poiando-se nos estudos desenvolvidos pelo professor Rudin no Instituto alemão de pesquisas psiquiátricas de Munique e apresentados no I Congresso Internacional de Higiene Mental realizado em Washington, em 1930, Lopes (1931) enfatiza a importância da eugenia para o movimento de higiene mental:

[...] todos os indivíduos, tarados, mal são nascidos, precisam naturalmente, sem restrição, da melhor e mais ampla higiene mental. Seria, pois, grandeerro, acreditar-se que nos mal es hereditários nada se pode conseguir com a higiene mental. Primeiramente, é certo, melhor seria não nascessem tais indivíduos, e isto mesmo quer agora a eugenia (p.149).

Caldas (1930), por sua vez, afirma: “Não sei como se possa fazer higiene mental, no seu sentido mais lato, sem levar em conta os consel hos eugênicos"' (p. 36).

\section{A deficiênCIA MENTAL SOB O PONTO de VISTA HIGIENISTA}

Encontramosnos ABHM uma variedade determinologias empregadas como sinônimo de deficiência mental, tais como: idiotia, fraqueza de espírito, imbecilidade, debilidade mental, déficit mental, retardamento, anormalidade, desvio, doença, etc. 
Para Lopes (1930a), idiotia era um déficit mental consecutivo a uma parada do desenvolvimento psíquico, ocorrentejá na vida fetal, ou nos primórdios da vida extra-uterina, cuja sintomatologia o leigo em psiquiatria jamais seria capaz de diferenciar de alguns outros estados mórbidos como, por exemplo, certas demências.

Conforme Pacheco e Silva (1939-40), a debilidade mental ou fraqueza de espírito tinha diferentes graus, indo desde a idiotice até as formas de leve retardamento mental. As causas da debilidade psíquica eram múltiplas, al gumas pré-natais, outras que atuavam após o nascimento da criança. Entreestas últimas, predominavam as infecções queselocal izavam nos centros nervosos, determinando inflamação das meninges e do cérebro, donde lesões mais ou menos graves que impediam o desenvolvimento intelectual.

A Sociedade Pestalozzi do Brasil, instituição "destinada a proteger a infância anormal e preservar a sociedade e a raça das influências nocivas da anormalidade mental", considerava anormal "todo ser que, por sua condição hereditária, ou acidentes mórbidos ocorridos na infância, não pôde, por falta de inteligência, ou distúrbios de caráter, adaptar-se à vida social com os recursos comuns ministrados só pela família, ou pela escola pública primária". (FATOS E COMENTÁRIOS, 1933b, p. 329 e 330).

Enquanto no Brasil existiam poucas instituições especializadas no atendimento educacional destinado aos deficientes mentais, deacordo com Lopes (1925), na Itália, a Liga de H igienee Profilaxia M ental estevefortementeenvolvidana organização da assistência médico-pedagógica para crianças deficientes. O regime escolar especial era indicado para o grupo de crianças denominadas "falsos anormais" e para os "verdadeiros anormais da inteligência e do caráter", isto é, débeis e instáveis. Neste último grupo também eram inseridos os anormais dos sentidos e da palavra e ainda os adenóides, os distraídos, os débeis físicos e, por fim, os atrasados por motivos externos, sociais (p. 96).

Segundo Lopes (1925), para os falsos deficientes era recomendada a escola diferencial, que poderia ser anexa às escolas comuns, ao passo que para os verdadeiros anormais psíquicos era indicada a escola autônoma, completamente separada. No caso dos falsos deficientes, verificava-se que, removendo o defeito físico ou o estorvo social responsáveis pelo déficit psíquico de certas crianças, logo se começava a ver alterar-se o seu quociente intelectual até o nível normal de sua idade. A obtenção desse nivelamento tornava-se assim o objetivo das escolas diferenciais que deveriam ter o mesmo programa e horário das escolas comuns com ensino individualizado. As escolas autônomas, ao contrário, deveriam ter os programas das aulas divididos em dois períodos, férias reduzidas, horário especial, rotação escolar, ortofonia, etc. Em vista da permanente incapacidadedeadaptação dos anormais, o trabalho educativo deveria ser orientado para um dado ofício.

Cal das (1932b) faz referência ao ensino decrianças anormais no Canadá, ondeexistiam institutos públicos com capacidade de internato para 3.000 deficientes 
mentais e escolas para anormais, sendo que cerca de 6.000 crianças recebiam instrução em classes especiais.

$\mathrm{Na}$ Tchecoslováquia, existiam 180 cursos do ensino em questão, 11 internatos para meninos débeis mentais, quatro escolas maternais para crianças difíceis, seis classes para crianças paralíticas ealeijadas, uma dlasse para diminuídos da audição, outra para diminuídos da visão, duas classes ambulantes, quatro internatos para débeis físi cos e oito classes para crianças débeis nos institutos de surdos mudos (FATOSE COMENTÁRIOS, 1933a).

A o se referir à higiene mental nos Estados Unidos, Camargo (1945-46) vai apontar que o aumento espantoso do número de oligofrênicos deveria ser encarado com maior rigor, dentro do capítulo da prevenção das doenças mentais. Relata que a Conferência da Criança, realizada na Casa Branca em 1930, revelou existir, nos Estados Unidos, 850 mil oligofrênicos em idade escolar. Em 1945, calculava-sequeapenas $10 \%$ dos ol igofrênicos estariam internados equeos demais permaneciam na comunidade por falta de instalações para recolhimento e tratamento extra-mural. O autor ainda menciona que em certos Estados norteamericanos existiam amplas provisões para o tratamento de escolares retardados. Em M assachusetts, por exemplo, havia nas escolas e nas instituições mais de 900 classes especiais para retardados, com cerca de 12.000 alunos. Os diretores das escolas faziam no fim do ano uma relação dos al unos que estavam atrasados três ou mais anos no trabal ho escolar e os encaminhavam ao exame dos psiquiatras e psi cologistas. O resultado desse exame era encaminhado às autoridades escolares e sempre que havia dez ou mais crianças nessas condições, era criada uma classe especial na escola.

O trabalho das classes especiais, segundo Camargo, figuravam como ótimo fator na prevenção das doenças mentais, porquanto prevenia o desenvolvimento de um sentimento de inferioridade nas crianças que repetiam e não conseguiam avançar como os demais al unos.

Podemos observar a partir de Roxo (1939) que, no Brasil, o atendimento prestado aos deficientes mentais era precário em relação aos países citados. Este autor apresenta o debatesobrea questão deassistência às crianças anormais trazida pelos jornais da época, a propósito da idéia de criação de um grande recol himento para tal fim, em Minas Gerais ${ }^{4}$. Faz referência à existência de atendimento para essas crianças anexo a hospitais psiquiátricos e a instituições de caráter privado.

O mesmo ainda relata que o Dr. Haroldo Leitão da Cunha criou, em Petrópolis, um Sanatório-Escola para crianças anormais, o qual passou posteriormenteà direção do Dr. Mirandolino Cal das equeos professores M artagão Gesteira e Xavier de Oliveira fundaram um Sanatório-Escola na Gávea. O próprio Henrique Roxo, juntamente com o Dr. Eurico Sampaio, criaram no Sanatório da Rua Voluntários da Pátria uma seção para crianças.

\footnotetext{
${ }^{4}$ Sociedade Pestal ozzi de Minas Gerais.
} 
Essas iniciativas são aval iadas como um avanço, já que "há al guns anos atrás, pais que tinham o infortúnio de ter filhos anormais, não tinham onde os colocar, para educação e tratamento". Contudo, a internação da criança nestes estabelecimentos só seria possível se os pais dispusessem de altos recursos financeiros (ROXO, 1939, p.1).

O Instituto 7 de Setembro, criado em 1938, era de caráter público e destinava-se a crianças abandonadas. De lá as crianças eram encaminhadas para patronatos eescolas, onde não havia separação entrenormais eanormais. Segundo Roxo (1939) as crianças anormais poderiam ser divididas em dois grandes grupos: aquelas que tiveram uma lesão grave no encéfalo e que se tornaram idiotas, paralíticas, etc., eaquelas que, tend o tido uma lesão mais leve, seapresentam como desequilibradas, frontei riças, excitáveis, etc. O autor acreditava que em relação ao primeiro grupo nada se poderia fazer, "caberia ao Estado amparar os pais infortunados". Quanto ao segundo grupo, este poderia se beneficiar de uma intervenção médica (p.2).

Caberia ao Estado a tomada de providências quanto à ampliação e desenvolvimento de serviços deassistência às crianças anormais, reconhecidamente pobres. Desta forma, orientada num ofício compatível com a sua capacidade mental, a criança poderia trabal har em oficinas, nas quais haveria certa compensação aos dispêndios que com ela o Estado tivesse.

Para Cavalcante (1943), no que se refere à educação, os "retardados" poderiam ser divididos em três grandes classes: "os educáveis, os difíceis e os irremediavelmente ineducáveis" (p.17).

No grupo dos educáveis enquadravam-se os retardados pedagógicos ou falsos deficientes, ou seja, crianças deficientes por freqüência irregular à escola, por distúrbios endócrinos, por "vegetações adenóides", por vícios de educação no lar ou erros de técnica educacional na própria escola, assim como os subnutridos, os "sifiloclásicos", os intoxicados pela tuberculose, os portadores de gânglios hipertrofiados, enfim, as crianças vítimas das várias moléstias comuns na infância, que poderiam deixar seqüelas no sistema nervoso central.

Ao grupo dos difíceis pertenciam os retardados intelectuais com ou sem debilidade mental, os atrasados intelectuais por instabilidade, os atrasados intelectuais por perturbações do caráter eos atrasados perversos. Aí estão os débeis mentais, os esquizóides, os ciclotímicos, os "mitomaníacos", os "gliscróides", os paranóicos, os hiperemotivos e os psicastênicos. É neste grupo que se encontram os deficientes verdadeiros, "os atrasados intel ectuais, os instáveis, os pervertidos, os amorais, os desamorosos, os sem afeto, os caracteres duros, amorfos, indisciplinados e mentirosos" (CAVALCANTE, 1943, p.17).

O grupo dos irremediavel mente ineducáveis era formado pelos idiotas eos imbecis, ambos com graves lacunas psíquicas, isto é, os verdadeiros oligofrênicos, raramente encontrados no meio escolar, dada a gravidade das lacunas mentais. 
Caval cante (1943) ressal ta a necessidade imediata da criação de classes especiais nas escolas e realização de pesquisas sistemáticas para os deficientes mentais, bem como a organização de Institutos de Reeducação. Os exames periódicos de saúde, conforme o autor, facilitaria até certo ponto a pesquisa sistemática dos retardados mentais e, por conseguinte, um tratamento médico e pedagógico de resultados mais compensadores. O mesmo acreditava que o deficiente intelectual poderia e deveria ser, em épocas diversas do seu estudo escolar, colocado nas classes das crianças normais, como estímulo à sua reeducação.

A Sociedade Pestalozzi do Brasil, por sua vez, concebia que a educação da criança anormal deveria fornecer-Ihe meios para melhoramento de seu estado mental, moral esocial, de sorteque, na idadeadulta, ela “ pesasse o menos possível à sociedade" (FATOSE COMENTÁRIOS, 1933b, p. 329 e 330).

Conforme A ntipoff (1945-46), aSociedade Pestalozzi tinha por objetivo o estudo, o tratamento e o ajustamento social das crianças e adolescentes, cujo desenvolvimento mental, aptidões e caráter necessitassem de uma assistência individual, dentro de um ambiente médico-pedagógico especial mente orientado. Para ela, não havia necessidade absoluta de segregá-los em asilos especiais e retirálos do convívio com crianças ou adolescentes normais.

A ntipoff (1945-46) acreditava que os imbecis e mesmo certos idiotas poderiam ser "membros úteis da coletividade", desde que Ihe fossem dados o tratamento mais humano possível, muito respeito à sua dignidade dehomem, muita atenção às peculiaridades de sua estrutura bio-social e de seu caráter (p. 65).

Os ABHM fazem referência à criação de serviços de higiene mental, clínicas de orientação infantil einstitutos depsicologia que, dentre outros objetivos, atuaram na avaliação, diagnóstico e encaminhamentos médico-pedagógicos dos deficientes mentais.

Destacamos o Serviço M édico-E scolar deSão Paulo, quedesde 1917, soba direção do doutor $\mathrm{B}$. Vieira de Mello, dentre suas inúmeras atri buições, real izava a sel eção dos anormais, com especificação das deficiências observadas e do regime especial de que necessitavam, bem como com a criação de classes e escolas para eles e orientação técnica aos profissionais nelas atuantes.

O critério utilizado para avaliar a anormalidade seria o grau de inteligência em relação aos alunos da mesma idade, bem como a observação da atenção e da memória. Não se explicitava claramente o que seria inteligência, principal parâmetro para a classificação das crianças em supranormal ou precoce, subnormal ou tardio e normal.

Assim, dentro da classificação dos subnormais estariam os astênicos, indiferentes, apáticos, instáveis, irrequietos, impulsivos, ciclotímicos ou al unos que participam de uma outra categoria. Seriam, pois, sempre alunos portadores de defeitos pedagógicos. Os anormais pedagógicos seriam os dotados deintel igência e instrução em grau inferior à sua idade, por descuido ou defeito pedagógico. 
A tendendo aos ideais de educação higiênica previstos para a escola, conformeart. $7^{\circ}$ do decreto $n^{\circ} 9.872$ de 28 de dezembro de 1938, écriada, no Serviço de Saúde Escolar em São Paulo, a Seção de Higiene M ental Escolar, que dentre suas atribuições, previa a organização de "assistência médico-pedagógica aos deficientes mentais, de modo a assegurar-Ihes uma aprendizagem proveitosa e conseqüente elevação de seu rendimento social" (LIMA, 1985, p. 143).

Durval Marcondes, chefe desteserviço, orientava ecoordenava equipes multidisciplinares, formadas por médicos, psiquiatras, educadores, neurologistas e especialistas em psicologia, conforme modelo das clínicas americanas, que se ocupavam do atendimento dos casos-problema encaminhados pelas escolas públicas. Este atendimento, baseado no model o médico inspirado no Movimento deH igiene M ental, além do tratamento dos escolares, previa também orientação à família e à escola, tendo, entretanto, como foco o aprendiz.

Segundo Marcondes (1941), quando a professora observava que determinado aluno não se aplicava convenientemente aos estudos por motivos quefugiam à simples al çada da pedagogia, deveria comunicar ofato imediatamente ao referido serviço, que desde então o tomaria aos seus cuidados, verificando sese tratava de debilidade mental. Por meio de um corpo de visitadoras sociais eram verificadas as condições de meio familiar em que vivia o escolar, seus hábitos, seus antecedentes. Todos os exames clínicos e de laboratório eram feitos desde logo, procurando-se corrigir ao mesmo tempo qual quer anomalia de ordem física ou orgânica (p.88).

Sob esta perspectiva, citamos ainda os trabalhos desenvolvidos pela Seção de O rtofrenia e H igiene $M$ ental no Instituto de Pesquisas Educacionais, instalado no Rio de Janeiro em 1934 e dirigido por Arthur Ramos. Segundo Ramos (1939), o programa de ação deste serviço incluía a higiene mental preventiva dos pré escolares, a educação de pais, professores e visitadores, clínicas de hábitos e de direção da infância, exame médico-psicológico do escolar, orientação dos psiquicamente sãos, reajustamento dos mal-ajustados, formação mental do educador, formação do educador especializado, educação do público através de conferências, divulgação através do rádio, cinema, boletim, publicações, trabal hos de experimentação, originais e contraprova de experiências estrangeiras, entre outros trabal hos.

Em 1925 é criado o Instituto de P sicologia em Pernambuco, ligado ao Departamento de Saúde e Assistência, posteriormente transferido para o Departamento de Educação com a denomi nação del nstitu to de Seleção e O rientação Profissional, com objetivos de orientação e seleção de professores para escolas primárias, secundárias e profissionais; aplicação de testes pedagógicos, físicopsicológicos e diagnósticos em crianças excepcionais e realização de estudos de psicologia patológica (PERN AMBUCANO, 1930, p. 86).

Segundo Barreto (1933), o Instituto dePsicologia de Pernambuco atuou no diagnóstico das várias formas de "parada" do desenvolvimento intelectual: 
debilidademental, imbecilidadee idiotia, mediante a determinação da idade mental (I.M.) e do quociente intelectual (Q.I.) desses doentes.

Esteserviço, conforme relata Barreto (1933), realizava a descoberta das crianças anormais, no meio escolar, que eram submetidas a alguns testes de inteligência. O valor do Q.I. encontrado permitia uma classificação em grupos de fracos, médios efortes. Entreos fracos eram encontrados os ligeiramentedeficientes eos anormais. Os mesmos deveriam ser posteriormente aval iados pelo Serviço de Higiene Mental de forma a descobrir os falsos anormais, aqueles que, livres de causas acidentais, poderiam se transformar em indivíduos normais.

Duas vantagens desse serviço eram apontadas pelo autor: a) as pesquisas realizadas afastariam as observações involuntariamente subjetivas dos professores, motivadas pelo elemento afetivo e b) permitiriam resolver ou encaminhar para sua solução o problema das classes homogêneas.

A questão das classes homogêneas é debatida por vários higienistas como possibilidade de promover educação a todas as crianças, levando em consideração a etapa de desenvolvimento intelectual e psíquico em que se encontram. Aliada a essa idéia tem-se também a formação de classes especiais, cuja premissa básica é a expansão de oportunidade educacional para aquel es que não conseguem seguir com regularidade os processos de ensino.

\section{A DEFICIÊNCIA MENTAL: CONCEPÇõeS E ENCAMINHAMENTOS DOS EUGENISTAS}

Conforme art.10 dos Estatutos da LBHM, promulgado em 1923, por ocasião da sua fundação, um dos objetivos da mesma era oferecer "proteção eamparo no meio social aos egressos dos manicômios e aos deficientes mentais passíveis de internação" (BRASIL, 1925, p.223). Para incentivar a pesquisa e o intercâmbio dos profissionais desta área também foi criada uma seção de estudos sobre deficiência mental, extinta em 1928 com a reforma dos Estatutos. Como indica Boarini e Yamamoto (2004), após 1928, a Liga "reafirma seu estatuto para viabilizar, em outros termos, seus objetivos, que passam a ter como alvo principal o indivíduo normal e não o doente, a prevenção enão a cura", assumindo desta forma o projeto eugênico, cuja pretensão era regenerar os indivíduos para melhorar a sociedade (p.67).

Sob esta ótica, a ênfase das ações destinadas ao deficiente estariam baseadas em medidas de eugenia restritiva. Observamos nos ABHM que para os eugenistas a deficiência, princi palmente a mental, estava relacionada a problemas básicos desaúde, causadores de degenerescências etaras, como a sífilis, tuberculose e doenças venéreas, que predomi nam nas aglomerações urbanas, onde a pobreza ea falta de higiene se misturam. Sendo assim, os deficientes mentais deveriam ser proibidos de entrar no país enquanto imigrantes, impedidos de ingressar no meio militar, excluídos das fábricas e escolas através de processos seletivos esubmetidos a exames pré-nupciais eintervenções cirúrgicas para o controle de sua reprodução. 
Ao tratar sobre a seleção individual de imigrantes no programa de higiene mental, Moreira (1925) refere-se ao estado de N ova Iorque, que em 1824 introduziu em sua legislação dispositivos no sentido de impedir a entrada de alienados eatrasados mentais em seu território. Em 1838, a Comissão de Justiça do Congresso norte-americano recomendou a promulgação de leis proibitórias da entrada de idiotas, alienados, doentes de afecções incuráveis e condenados por crimes. Para Moreira, de nada serviria envidar esforços no sentido de mel horar as condições de saúde física e mental da população se tivesse semprea chegar novas levas de tais indesejáveis.

[...] devemos fazer sem distinção de raça ou nacionalidade uma seleção individual o mais que possível rigorosa sob o ponto de vista mental, isto é, não devemos receber imigrantes que apresentem perturbação mental congênita ou adquirida: nenhum idiota, nenhum imbecil evidente, nenhum demente de qualquer espécie, nenhum epiléptico, nenhum maníaco-depressivo, nenhum parafrênico, nenhum paranóico, nenhum doente de qualquer outra psicose definida poderá saltar em nenhum porto nacional (1925, p.115).

Segundo Pacheco e Silva (1925), o Brasil precisava de muitos braços para sua expansão, "mas degente sadia", que mel horasse as "nossas condições de vida" e que fosse, ao mesmo tempo, "um fator eugenético" (p.34).

Cardoso (1925) acrescenta que, segundo decreto $n^{\circ} .4247$, de6 dejaneiro de 1921, "todo estrangeiro mutilado, aleijado, cego, louco, mendigo, portador de moléstia incurável ou de moléstia contagiosa grave" deveria ser impedido de entrar no território nacional (p.142).

O 30 Congresso Brasileiro de N eurologia, Psiquiatria e M edicina Legal, realizado em 1928, conforme Oliveira (1932) sugere ao governo brasileiro que a LBH M faça a inspeção médico-psiquiátrica e eugênica de todos os imigrantes que se destinem ao Brasil.

Os deficientes mentais também deveriam ser excluídos do meio militar. Conforme Campos (1925), uma das medidas de higiene mental adotada no meio militar era a recusa eexclusão dos deficientes mentais enervosos. O autor menciona quenos Estados Unidos, através de testes organizados a partir de uma modificação da escala de Binet-Simon, aqueles que apresentavam situação psíquica muito inferior à média eram impedidos de entrar no batal hão. N as palavras de Campos, "se se fecham as casernas aos tarados físicos com mais forte razão deve-se fechálas aos tarados mentais, muito mais nocivos" (p.94).

Nas fábricas, os higienistas propunham aos industriais a presença de médicos clínicos familiarizados com os temas de psiquiatria e higienemental para realizar a sel eção profissional, afastando os operários débeis mentais eos deficientes sob o aspecto moral ou emotivo. Seguindo orientação de estudiosos como, por exemplo, Stocker, os higienistas sugeriam que "os débeis intelectuais poderiam prestar serviços em certos trabalhos puramente maquinais, sujeitos sempre, 
entretanto, a tutela médica" (LOPES, 1930f, p. 258).

No quese refere às medidas de controlesobre a constituição biológica, ao anal isar a questão da miséria em relação ao problema da natalidade, Kehl (1932) critica a medicina, a higiene social e a filantropia que protegem os fracos e degenerados enão deixam atuar a lei eterna da luta pela vida que garantia a vitória dos mel hores e impedia o acúmulo de incapazes e de nocivos à col etividade. Para Kehl, o planeta cobriu-se de resíduos, gente de "baixa categoria física, psíquica e intelectual, que come e não produz, que sem trabalhar, agita-se nocivamente, perturbando o equilíbrio social" eas ceifadeiras de outras épocas não podem mais agir com liberdade. "Vive-semais. M orre-semenos. Em compensação, também, os desocupados seacumulam, a mendicidade aumenta e o número de débeis mentais se multiplica assustadoramente!" (p.8e9).

Diante de tal problema o autor é enfático:

[...] ou a humanidade resolve seguir a prescrição galtoniana ou então prosseguiremos na babélica confusão em que vivemos, até que, por um contragol pe violento da natureza, se processe, em massa, rapidamente, a depuração do planeta pela eliminação brutal dos resíduos humanos nele acumulados (KEHL, 1932, p.10).

Seguir a prescrição galtoniana significa, dentre outros princípios, adotar medi das de purificação da raça através da esterilização e proi bição de casamentos.

Conforme Porto-Carrero (1933), sob o ponto de vista eugênico, seria ideal que só pudessem se casar indivíduos completamente hígidos eem condições de procriar filhos física e psiquicamente perfeitos. Para ele o interesse da espécie estava acima do interesse da sociedade e do indivíduo, que nada mais é do que "a célula periodicamente renovável do grande organismo da espécie" (p.89).

Porto-Carrero (1933) atribuía ao Estado a responsabilidade de prover o bom resultado das uniões reprodutoras na espécie humana. Para esse fim, propunha o exame médico pré-nupcial, a exemplo do que já ocorria em países como Estados Unidos, Equador, Turquia, França, etc.

Lopes (1933) acreditava que o examemédico prénupcial, além defator de pura eugenia, poderia servir como elemento de profilaxia da infelicidade conjugal. A mesma defende a esterilização facultativa no caso do indivíduo ser reprovado no exame pré-nupcial. Assim como Porto-Carrero, a autora considera que para a natureza o indivíduo não é nada, a espécie é tudo.

A natureza é impiedosa: condena os doentes. [...] É isto mesmo o que fazem alguns povos em que os doentes evel hos são abandonados sem recursos assim como os nascidos defeituosos.

Se a sociedade se regesse somente por leis biológicas se aproximaria a estas leis naturais: a destruição dos débeis, inaptos, surdo-mudos, alienados, hidrocéfalos, etc... (p.105). 
No que se refereespecificamente aos deficientes mentais, Lopes (1933) cita o trabal ho de um autor germânico, o Dr. Hübner, de Bonn. O mesmo observa que o consel heiro matrimonial, em face dos casos leves (os graves evidentemente seriam sempre excluídos) deveria guiar-se menos pelo déficit intelectual propriamente dito do que pel a presença ou ausência de certos sintomas acessórios, que tornam penoso o convívio com tais indivíduos (excitabilidade, casmurrice, tendência à mentira, hipersexualidade e outros).

A esterilização, enquanto medida de prevenção dos mal es hereditários, era defendida por vários higienistas; dentre eles, citamos: Juliano M oreira, Ernani Lopes, Mirandolino Caldas, J. P. Porto-Carrero, Murillo Campos, Heitor Carrilho, Alberto Farani, etc.

Reconhecida a importância dessa medida eugênica para os higienistas, os ABHM de 1934 publicam na íntegra a lei alemã de esterilização dos doentes transmissores de taras. Esta lei considerava alvo de esterilização indivíduos que padeciam de doenças hereditárias: debilidade mental congênita, esquizofrenia, loucura circular (maníaco-depressiva), epilepsia, coréia, cegueira, surdez, grave deformidade corporal e quem sofria de al coolismo grave.

Cabe pontuar que os ABHM abordam muitas vezes a temática da deficiência mental associada à questão da criminalidade e da marginal idade.

Em resenha do artigo intitulado "Serão os débeis mentais criminosos?" publicado em janeiro de 1929, de autoria de George L. Wallace, ilustre membro da Liga deHigieneM Mental dos Estados Unidos, Lopes (1930b) reproduz os argumentos do autor que questiona, principal mente, a identificação da debilidade mental com delinqüência por meio dos testes psicométricos. Neste sentido, antes da criação dos testes psicométricos o critério adotado para definir a debilidade mental era a incapacidade social. A partir dos exames sistemáticos pel os testes psicométricos, conforme a escala de Binet-Stanford, todo indivíduo cujo Q.I. fosse abaixo de 75 era considerado débil mental. Esses exames real izados em delinqüentes recolhidos em instituições correcionais revelaram grande porcentagem de quocientes limítrofes dessa cifra desclassificadora eesse fato natural mentelevou, no primeiro momento, a identificar debilidade mental com delinqüência.

O autor observa que, antes dos testes de Binet, a proporção de débeis mentais na população americana era computada em um a dois por mil. Desde, porém, que os testes criaram o débil mental superior, tal proporção passou a ser de dois a três por cento.

Na opinião do mesmo, os débeis mentais que entram em conflito com a lei são prontamente descobertos e presos, ao passo que os delinqüentes intel igentes conseguem escapar. A lém disso, quando processados, os delinqüentes inteligentes, têm sempremais recursos que os débeis para conseguirem absolvição, acrescendo, por fim, queos delinqüentes débeis, quando condenados, sebeneficiam menos da liberdade condicional. 
Sendo assim, existe uma diferença entre "débeis mentais delinqüentes" e "delinqüentes débeis mentais". Os primeiros são muito mais numerosos e caracterizam-se pela preponderância do defeito mental sobre o defeito moral esão levados a delinqüir sob a influência do meio social. Os segundos caracterizam-se pela predominância das lacunas morais e podem delinqüir, embora o ambiente social Ihe seja favorável. Para a realização da profilaxia da delinqüência o autor sugerea criação declínicas de neuropsiquiatria infantil eclínicas dehábitos (p.23).

Ao tratar sobre a Reforma do Código Penal Brasileiro, Lopes (1930a) discute o uso do termo idiotia no artigo 29, que em sua primeira cláusula sugerea imputabilidade aos que se encontram em estado de alienação mental, idiotia ou inconsciência. A dvoga que, em vez de idiotia, seria admissível usar as expressões fraqueza da mente e fraqueza do espírito, porque tais expressões mais amplas incluiriam não só a idiotia como os outros estados de parada de atraso de desenvolvimento psíquico (imbecilidade, debilidade mental), que também são compatíveis com a plena imputabilidade.

Quanto aos menores incorrigíveis, Lopes (1930e) diz quesob o aspecto intelectual, podem-se considerar insuscetíveis de melhoria ou correção, isto é, incorrigíveis, todos os atrasados ou deficientes intelectuais. Para Lopes, "o débil pode por certo ser instruído; nunca, porém, será capaz de resolver questões que exijam um nível de raciocínio superior ao da sua idade mental" (p.242).

\section{CONCLUSÃO}

A través da leitura e análise dos $A B H M$, periódico que veiculava as idéias higienistas e eugenistas da LBH M procuramos identificar as concepções eo atendimento escolar destinado aos deficientes mentais. De uma forma geral, verificamos quea LBHM expressa opiniões diversificadas quanto à concepção eàs medidas de intervenção propostas para os deficientes mentais. De um lado, encontramos as propostas de higienização da população através da adaptação do indivíduo ao meio social, a ser al cançada, por sua vez, com a formação de hábitos sadios gerados através da educação escolar eespecificamente da educação higiênica. Deoutro, temos a defesa de uma posição eugênica radical, queapregoa a purificação da raça, a esterilização e exclusão dos ditos degenerados (leprosos, loucos, idiotas, epilépticos, cancerosos, nefrolíticos, tuberculosos, prostitutas e vagabundos), incluindo, entre estes, os deficientes mentais.

No que se refere à concepção de deficiência mental adotada pelos higienistas, observamos, a partir dos ABH M, que uma variedade determinologias são empregadas como sinônimo de deficiência mental, tais como: idiotia, fraqueza de espírito, imbecilidade, debilidade mental, déficit mental, retardamento, anormalidade, desvio, doença, etc.

Os encaminhamentos propostos pelos higienistas aos deficientes mentais variavam conforme o grau de comprometimento intel ectual. Os mesmos 
propunham a criação deformas diferenciadas deatendimento em dínicas, institutos psicopedagógi cos e centros de reabilitação, admitindo inclusive que os deficientes mentais atendidos em classes especiais anexas às escolas pudessem posteriormente ser incluídos em classes regulares, o que não acontecia de fato.

Quando existiam turmas anexas às escolas primárias, o propósito não era combater a segregação. Citando Vial, Jannuzzi (1992) reitera: “Essas classes passam a funcionar nas mesmas escolas queas crianças normais, mas têm a entrada e o recreio separados: é a turma dos loucos e a turma dos normais" (p. 29).

De uma forma geral, o ensino voltado para o deficiente mental se restringia à aquisição de hábitos higiênicos e alimentares e de algumas regras sociais. Deacordo com o grau de comprometimento intelectual, também deveriam ser preparados para executar atividades laborais simples.

A análise do atendimento escolar oferecido ao deficiente mental nas primeiras décadas do século XX, segundo o ideário higienista, nos revela que a defesa da educação dos indivíduos com deficiência mental foi feita em nome da "ordem e do progresso", pois que evitaria a proliferação de criminosos e desajustados de toda espécie, ao mesmo tempo em que implicaria a economia dos cofres públicos e dos bol sos de particulares, diminuindo gastos com a manutenção de manicômios, asilos e penitenciárias.

A educação do deficiente mental também foi realizada em função do aluno normal. De acordo com Jannuzzi (1992), as escolas só deveriam aceitar matrículas dealunos quenão prejudicassem o bom andamento dos al unos normais, tornando assim mais produtivo o ensino nas classes comuns, destinadas aos mais favorecidos. A partir das experiências levadas a efeito com crianças "anormais", também seria possível generalizar procedimentos pedagógicos para o conjunto do sistema escolar.

Por outro lado, para os adeptos da eugenia, os deficientes mentais eram considerados nocivos à sociedade. Os mesmos não deveriam existir, muito menos receber algum tipo de assistência ou educação. As medidas eugênicas destinadas aos deficientes mentais se denominavam profiláticas e visavam "reduzir, até eliminar, paulatinamente, por processos biológicos os subnormais e anormais, impedindo a reprodução de indivíduos apresentando taras nervosas e psíquicas" (KEHL, 1932, p. 9).

Kehl (1932) defendia algumas idéias polêmicas, como a esterilização compulsória de "certos al ienados ecriminosos" ea prática da "filantropia sel etiva", orientada no sentido eugênico de amparar os elementos produtivos e, sobretudo, os tipos superiores da coletividade. Com base num tipo médio de indivíduo, que apresenta bom funcionamento de todos os órgãos ecujas partes do corpo guardam relativa proporção entresi, sem doenças nem perturbações de qualquer natureza, Kehl denuncia a filantropia por favorecer os medíocres, os doentes e incapazes, aumentando assim a parte residual da humanidade. 
É necessário destacar queestas idéias epropostas de encaminhamentos que buscavam encontrar um lugar para o deficiente mental na sociedade brasileira não foram geradas a partir desta ou daquela idéia de um indivíduo particular. Tal ideário fez parte de um conjunto de preocupações e tentativas de sanar "o atraso do passado" e fazer do Brasil uma grande Nação. Isto significa que a criação da necessidade de educação para os deficientes mentais só pode ser entendida como uma produção histórica de um determinado período.

A o proporem explicações para problemas gerados na coletividadecomo se fossem gerados por questões individuais, as propostas higienistas e eugenistas escamoteavam a existência de contradições e naturalizavam as relações sociais. Se o indi víduo éque não tinha o conhecimento sobre hábitos sadios, arrumava-se um jeito de instruí-lo. Se o indivíduo não mantinha comportamentos considerados à altura deuma nação que pretendia ser desenvolvida, procurava-seinstituir a ordem através da educação higiênica emoral no âmbito familiar, nas fábricas enas escolas. A prevenção aparece como discurso salvacionista, assim como a criança e sua educação como redentores de um povo medíocre. Esse projeto de redenção desenvolveu-se prevenindo tudo o que fosse considerado inoportuno e excluindo o que não fora possível prevenir.

Em que pese a determinação e o ideal dos médicos higienistas das primeiras décadas do século XX, o tempo transcorrido comprova quea crise vivida pela sociedade brasileira desta época longe estava de encontrar uma solução, circunscrevend o o problema à má formação física, psíquica emoral dos indivíduos em particular.

\section{REFERÊNCIAS}

ANTIPOFF, H. Espírito e atividade da Sociedade Pestalozzi do Brasil. A rquivos Brasileiros de Higiene M ental, Rio de Janeiro: v. 16, 17, p.59-69, 1945-1946.

BARRETO, A. P. A atividade do Instituto de Psicologia de Pernambuco. In: ACTAS DE REUNIÃO DA LIGA. A rquivos Brasileiros de HigieneM ental, Rio deJaneiro, v. 6, n. 2, p. 174 178, 1933.

BOARINI, M.L.; YAMAMOTO, O. H. Higienismo eeugenia: discursos quenão envelhecem. Psicologia R evista, São Paulo, v. 13, p. 59-71, 2004.

BRASIL. Decreto-lei n. 4.778. Estatutos da Liga Brasileira de Higiene Mental. Capítulo I: denominação, organização, sede efins da Liga. A rquivos Brasileiros de H igiene M ental, Rio de Janeiro, v. 1, n. 1, p. 223-234, 1925.

CALDAS, M. Os A rquivos Brasileiros de Higiene Mental. A rquivos Brasileiros de Higiene M ental, Rio deJaneiro, v. 2, n. 1, p.1-2, 1929.

. O Congresso de higiene mental ea eugenia. A rquivos B rasileiros de Higiene $M$ ental, Rio de Janeiro, v. 3, n. 2, p.35-36, 1930.

. A Eufrenia - ciência da boa cerebração. A rquivos Brasileiros de H igiene M ental, Rio de Janeiro, v. 5, n. 2, p.29-40, 1932a. 
CALDAS, M. A higienemental no estrangeiro. A rquivos Brasileiros deH igieneM ental, Rio de Janeiro, v. 5, n. 2, p.149-162, 1932b.

CAMARGO, O. A higienemental nos Estados Unidos. A rquivos Brasileiros deH igieneM ental, Rio de Janeiro, v. 16 e 17, n. único, p. 17-30, 1945-46.

CAMPOS, M. N otas sobrea higienemental no exército. A rquivos Brasileiros deH igieneM ental, Rio de Janeiro, v. 1, n. 1, p. 91-100, 1925.

CARDOSO, Á. Subsídios à legislação sobreimigração. A rquivos B rasileiros de H igiene $M$ ental, Rio de Janeiro, v. 1, n. 2, p. 141-146, 1925.

CAVA LCANTE, A. L. Crianças A normais. A rquivos Brasileiros de H igiene $M$ ental, Rio de Janeiro, v. 14, n. 1, p. 17-20, 1943.

FATOSE COM ENTÁRIOS. O ensino das crianças anormais na Tchecoslováquia. A rquivos Brasilei ros de Higiene M ental, Rio de Janeiro, v. 6, n. 1, p.57-62, 1933 .

. A primeira publicação da Sociedade Pestal ozzi deM inas Gerais. A rquivos B rasileiros de H igiene M ental, Rio de Janeiro, v. 6, n. 3, p.328-335, 1933b.

FONTEN ELLE, J. P. Higiene mental e educação. A rquivos Brasileiros de H igiene M ental, Rio deJaneiro, v. 1, n. 1, p.1-10, 1925.

JAN NUZZI, G. M. A luta pela educação do deficiente mental no Brasil. Campinas: Autores Associados, 1992.

KEHL, R. F. Considerações em torno da pletora humana. A rquivos Brasileiros de Higiene M ental, Rio deJaneiro, v. 5, n. 2, p. 5-10, 1932.

. Lições de Eugenia. 2. ed. Rio de Janeiro: Francisco Alves, 1935.

LIMA, G. Z. Saúde escolar e educação. São Paulo: Cortez, 1985.

LOPES, C. A. Introdução ao estudo da higienemental. A rquivos Brasileiros deH igiene M ental, Rio deJaneiro, v. 15, n. 1, p.69-71, 1944.

LOPES, E. A propósito das recentes disposições ministeriais para a educação das crianças deficientes. In: RESENHAS E ANÁLISES. A rquivos Brasileiros de Higiene M ental, Rio de Janeiro, v. 1, n. 2, p. 95-97, 1925.

. A psiquiatria em nossas leis penais. A rquivos Brasileiros de $\mathrm{H}$ igiene $\mathrm{M}$ ental, Rio de Janeiro, v. 3, n. 1, p. 6-11, 1930a.

. Serão os débeis mentais criminosos? A rquivos Brasileiros de H igiene $M$ ental, Rio de Janeiro, v. 3, n. 1, p. 22-23, 1930b.

Reunião da Seção de Propaganda e Publicidade. A rquivos Brasileiros de Higiene $\bar{M}$ ental, Rio de Janeiro, v. 3, n. 2, p. 63-66, 1930c.

. Trabalhos deanti-alcoolismo. A rquivos Brasileiros de Higiene M ental, Rio deJaneiro, v. 3, n. 3, p. 91-94, 1930d.

7, p. 241-246, 1930e.

Menores incorrigíveis. A rquivos Brasileiros de H igiene M ental, Rio de Janeiro, v. 3, n.

. A higiene mental do operário. A rquivos Brasileiros deH igiene M ental, Rio deJaneiro, v. 3, n. 7, p. 257-258, 1930f. 
LOPES, E. A significação da eugenia e da genética para a higiene psíquica. A rquivos Brasileiros de Higiene M ental, Rio de Janeiro, v. 4, n. 2, p.147-151, 1931.

LOPES, J. M. Em torno do exame pré-nupcial. A rquivos Brasilei ros de H igieneM ental, Rio de Janeiro, v. 6, n. 2, p. 104-122, 1933.

MARCONDES, D. A Higienemental dos escolares. A rquivos Brasileiros de Higiene M ental, Rio de Janeiro, v. 13, n. 1, p. 87-90, 1941.

MOREIRA, J. A sel eção de imigrantes no programa da higiene mental. A rquivos B rasileiros de Higiene M ental, Rio de Janeiro, v. 1, n. 1, p. 109-115, 1925.

NOTA AOS LEITORES. A rquivos Brasileiros de H igiene M ental, Rio de Janeiro, v. 18, n. 1 , 1947.

OLINTO, P. Higiene mental esuas relações com o urbanismo. A rquivos Brasileiros de H igiene M ental, Rio deJaneiro, v. 13, n. 1, p. 17-20, 1941.

OLIVEIRA, X. Da profilaxia mental dos imigrantes. A rquivos Brasileiros de H igiene $M$ ental, Rio de Janeiro, v. 5, n. 1, p. 16-38, 1932.

PACHECO E SILVA, A. C. Imigração ehigienemental. A rquivos Brasileiros deH igieneM ental, Rio deJaneiro, v. 1, n. 2, p. 27-35, 1925.

. Rudimentos de higiene mental. A rquivos B rasileiros de H igiene $M$ ental, Rio deJaneiro, v. 12, n. 3e 4, p. 52-60, 1939-40.

PERN ANBUCANO, U. A psicologia em Pernambuco. A rquivos Brasileiros de H igieneM ental, Rio de Janeiro, v. 3, n. 1-9, p. 85-90, 1930.

PORTO-CA RRERO, J. P. O exame pré-nupcial como fator eugênico. A rquivos Brasileiros de Higiene M ental, Rio deJaneiro, v. 6, n. 2, p. 87-94, 1933.

RAMOS, A. A criança problema: a higiene mental na escola primária. Rio de Janeiro: Companhia Editora Nacional, 1939.

REIS, J. R. F. Degenerando em barbárie: a hora ea vez do eugenismo radical. In: BOA RINI, Maria Lucia. (Org.). H igieneeraça como projetos: higienismo eeugenismo no Brasil. Maringá: EDUEM, 2003. p. 185-216

ROXO, H. Problemas dehigienemental. A rquivos Brasileiros de H igieneM ental, Rio deJaneiro, v. 12, n. 1 e 2, p.1-4, 1939.

Recebido em 03/ 12/ 2007

Reformulado em 11/ 06/ 2008

A provado em 16/ 08/ 2008 